\title{
Jay Wright Forrester (1918-2016): His Contribution to the Concept of Overshoot in Socioeconomic Systems
}

\author{
Ugo Bardi ${ }^{1}$
}

Received: 23 November 2016/Accepted: 24 November 2016/Published online: 30 November 2016

(C) Springer International Publishing Switzerland 2016

\begin{abstract}
The recent death of Jay Wright Forrester has generated several obituaries in the press describing his many achievements. However, often his involvement in the somewhat controversial issue of «World Modeling» and of «The Limits to Growth» has gone unmentioned or only barely mentioned [see, e.g., the article that appeared in The New York Times (Hafner in Jay W. Forrester dies at 98; a pioneer in computer models, 2016)]. In this commentary, I aim at providing a brief discussion of one of Forrester's main scientific achievements: the introduction of the concept of overshoot and collapse as applied to socioeconomic systems.
\end{abstract}

Keywords System dynamics - World modeling - Resource depletion · Jay Forrester · Limits to growth

Today, the concept of societal collapse is inextricably linked to the work that the Club of Rome had commissioned from a group of MIT researchers and that was published in 1972 under the title «The Limits to Growth» (Meadows et al. 1972). The often bitter debate that followed [see Bardi (2011)] is familiar to many of us, but it may have obscured the fact that, until the 1970s, the concept of "overshoot and collapse" was unknown in relation to socioeconomic systems. In the book «The Human Quality» (Peccei 1977), Aurelio Peccei, the first president

The original version of this article was revised: "Jay Write Forrester" has been changed to "Jay Wright Forrester" in the title and throughout the article.

Ugo Bardi

ugo.bardi@unifi.it

1 Dipartimento di Chimica, Università di Firenze, Via della Lastruccia 3, 50019 Sesto Fiorentino, Fi, Italy of the Club of Rome, tells the story of what he called the «problematique» that was the object of the Club's attention. From what Peccei writes in this book, and also in his previous "The Chasm Ahead" (Peccei 1969), it is clear that the major element of the problematique was overpopulation, which was seen as bringing famines, environmental destruction, unrest, wars, and other forms of human suffering. It does not appear that Peccei and his colleagues at the Club considered limits to material resources or pollution levels to be important, nor that their combination could lead to the collapse of the modern human civilization. So, the policies that the Club of Rome initially advocated were related to the negative results of overpopulation: a fair distribution of wealth, international collaboration, and the need for world peace. Only much later, the Club came to be associated with the concept of «The Limits to Growth», the title of the 1972 report, and a systems view of interacting factors in the fate of civilization.

At the beginning, Peccei and the other members of the Club were part of the mainstream vision of their times. Certainly, the idea that societies fail and disappear from history was qualitatively known at least from the time of Gibbon's monumental «Decline and Fall of the Roman Empire» (1776). After Gibbon, Thomas Malthus is commonly credited with predicting collapse in his «An Essay on the Principle of Population» (Malthus 1798). We are often looking at Malthus' work through the lenses of modern knowledge, accusing him of having been «wrong» because he had predicted disasters that didn't occur. But, re-reading the «Essay», we may be surprised at discovering that it doesn't contain «wrong predictions». Malthus never speaks of collapses to come; you won't even find the term in the book. His main theme is how population growth is kept in check by natural factors such as famines and epidemics. His idea was that, if the number of humans was to 
exceed the limit set by food production, nature would intervene by cropping the excess and the number of humans would return to the limit. Malthus understood the concept that we now call "carrying capacity," but not the basis or implications of «overshoot».

It took time for the concept of overshoot and collapse to make inroads into the thinking of people concerned with the future of humankind. We may find the idea of limited or finite resources expressed for the first time by Jevons in "The Coal Question" (Jevons, 1866). In 1956, Marion King Hubbert proposed his theory of the peaking and decline of oil production (Hubbert 1956), again related to the limits to the available resource and to the eventual collapse in production. In other areas of science, the collapse of biological populations was well known from the time of Lotka (1925) and of Volterra (1928). In mathematics, the discontinuities shown by some function were examined already in the mid-nineteenth century in terms of the "Gibbs-Willbraham" phenomenon (Hewitt and Hewitt 1979). This series of studies gave rise of the use of the term "overshoot" in control theory and in electronics, as well as that of "feedback." So, the concept of societal decline taking the shape of overshoot and collapse was basically unknown until the development of world dynamics.

Jay Wright Forrester himself has told the story of his initial efforts to develop the theory and the practice of system dynamics (Forrester 2007). Forrester's early work was in control systems and control engineering. This training is probably why he was familiar with the concept of "overshoot," which occurs when a signal exceeds the desired level to return to it through a series of oscillations in feedback-dominated systems. Cross-fertilization between different fields of science and between different physical systems is often the origin of scientific progress, and this is what happened when Forrester moved from control engineering to studying business systems. It was a field that he dubbed "business dynamics" and that he tackled initially by simple pencil and paper calculations. In time, he developed a complete programming language "DYNAMO" that was used to solve systems formed of several coupled differential equations. With this tool, he started exploring socioeconomic systems, launching the field that he called «urban dynamics». The next stage was to be "World Dynamics," but this field was still to be developed when Forrester and Peccei met in 1970.

As related by both Peccei and Forrester, the involvement of the Club of Rome led to a rapid acceleration of the work on world dynamics. In 1971 Forrester published "World Dynamics" (Forrester 1971), which was the first study that quantitatively modeled the collapse of society resulting from a combination of finite resources, pollution, and overpopulation. Forrester's work was at the origin of the better known «The Limits to Growth» study that was published one year later, in 1972, as a report commissioned by the Club of Rome. The story is told by Dennis Meadows as follows (private communication):

The "Limits to Growth" project would not have happened without him [Forrester]. He brought the COR Executive Committee to MIT, where I persuaded them to hire me for a major project. We could not have succeeded without Jay's conceptualization of the problem, as expressed in World Dynamics. Nor could we have worked without using his methods of social system feedback analysis. I have always acknowledged that working as his student gave me the skills I needed for a lifetime of work.

These studies, "World Dynamics" and "The Limits to Growth", were fundamentally based on the concept of overshoot and collapse and also to that of "carrying capacity." Forrester clearly spoke of "population collapse" and the concept of overshoot was implicit in the structure of his model and in the results of the calculations. "The Limits to Growth" explicitly showed the possible trajectories of overshoot and return in a schematic diagram on page 92 of the 1972 edition, explicitly using the terms "overshoot" (p. 94) and "collapse" (p. 98) (Meadows, et al. 1972). These two books were based on these highly innovative ideas that were applied for the first time to social systems. So innovative were these concepts that they can be said to have been revolutionary, and it is known that revolutionary ideas often have a hard time being accepted. What happened is well known: decades of bitter debate that led to the diffusion of the legend of "wrong predictions," the responsibility for which is often attributed to the Club of Rome rather than to Forrester or to the authors of "The Limits to Growth" (Bardi 2011). That this legend is totally groundless has not halted its wide diffusion that continues to this day. The concepts of overshoot and collapse were to go through the fate of the "new truths" that Thomas Huxley said couldn't avoid being born as heresies (Huxley 2011).

Yet, these concepts were proposed again by Catton (1982), and today, they are part of the intellectual foundation of the study of sustainability. We are also seeing a renewed interest in world modeling, with new research groups being formed and new methods being tested. In view of the desperate need for quantitative models to arbitrate between widely differing political positions and perceptions, as well as the need to reduce greenhouse gas emissions before it is too late, world modeling is a tool that we can't afford not to use. And the credit for having made this tool available to us goes in large part to the revolutionary ideas of Jay Forrester. 
Acknowledgements The author thanks Dennis Meadows and Ilaria Perissi for their comments and suggestions.

\section{References}

Bardi U (2011) The limits to growth revisited. Springer, New York Catton W (1982) Overshoot, the ecological basis of revolutionary change. Illinin Books Edition, Chicago

Forrester J (1971) World dynamics. Wright-Allen Press, Cambridge

Forrester JW (2007) System dynamics-a personal view of the first fifty years. Syst Dyn Rev 23:345-358. doi:10.1002/sdr.382

Hafner K (2016) Jay W. Forrester dies at 98; a pioneer in computer models. New York Times, Nov 17, 2016

Hewitt E, Hewitt RE (1979) The Gibbs-Wilbraham phenomenon: an episode in Fourier analysis. Arch Hist Exact Sci 21:129-160. doi:10.1007/BF00330404

Hubbert MK (1956) Nuclear energy and the fossil fuels. In: Spring meeting of the southern district division of production, American Petroleum Institute, San Antonio, TX, USA
Huxley T (2011) "The coming of age of the origin of species" collected essays, vol 2. Benediction Classics, Oxford

Jevons WS (1866) The coal question, 2nd revised edn. Macmillan, London

Lotka Alfred J (1925) Elements of Physical biology. Williams and Wilkins Company, Baltimore

Malthus T (1798) An essay on the principle of population: or, a view of its past and present effects on human happiness. J. Johnson, London

Meadows DH, Meadows DL, Randers J, Bherens W III (1972) The limits to growth. Universe Books, New York

Peccei A (1969) The chasm ahead. McMillian and Company, New York

Peccei A (1977) The human quality. Pergamon Press, Elmsford

Volterra V (1928) Variations and fluctuations of the number of individuals in animal species living together. J Cons Int Explor Mer 3:3-51. doi:10.1093/icesjms/3.1.3 